\title{
LA EDUCACIÓN POPULAR: ENTREVISTA CON ÓSCAR JARA HOLLIDAY
}

\author{
THE POPULAR EDUCATION: \\ INTERVIEW WITH ÓSCAR JARA HOLLIDAY
}

\author{
Óscar Jara Holliday*
}

Fecha de recepción: 01/07/2019

Fecha de aceptación: 31/07/2019

Resumen: En la presente entrevista, el destacado educador popular y sociólogo peruanocostarricense, Dr. Óscar Jara Holliday, explica los orígenes y particularidades de la educación popular. Según sus propias palabras, la educación popular "debería tener una noción política transformadora, es decir, una educación que debería permitir que la sociedad pudiera tener una estructura social, democrática, justa, equitativa y que, por lo tanto, los sujetos protagonistas de los procesos educativos tienen que ser quienes impulsen esos procesos políticopedagógicos. De esa visión político-pedagógica de un proyecto popular de sociedad, podemos hablar de una educación popular".

Palabras claves: Óscar Jara Holliday; entrevista; educación popular; América Latina; estudios sociales; historia.

Abstract: In this interview, the prominent Peruvian-Costa Rican popular educator and sociologist, Dr. Óscar Jara Holliday, explains the origins and particularities of popular education. In his own words, popular education "should have a transformative political notion, that is, an education that should allow society to have a social, democratic, fair, equitable structure and, therefore, the main subjects of the educational processes must be those that

* Peruano-costarricense. Sociólogo y educador popular. Director general del Centro de Estudios y Publicaciones Alforja en Costa Rica. Coordinador del Programa Latinoamericano de Apoyo a la Sistematización de Experiencias del Consejo de Educación Popular de América Latina y El Caribe (CEAAL). Correo electrónico: oscar@cepalforja.org Entre sus obras destacan: Educación popular: la dimensión de la acción política (1981); Los desafíos de la educación popular (1984); Aprender desde la práctica (1989); Para sistematizar experiencias (1994); Apropiarse del futuro (2006); Educación y cambio social en América Latina (2009); y La sistematización de experiencias. Práctica y teoría para otros mundos posibles (2012). Investigador de referencia en la teoría y la práctica de la sistematización de experiencias, es fundador de la Red Alforja junto a Carlos Núñez - del Instituto Mexicano para el Desarrollo Comunitario (IMDEC) - y Raúl Leis -del Centro de Estudios y Acción Social Panameño del Ceaspa-. Ha sido promotor, coordinador y animador de procesos de educación popular en diferentes países, principalmente, en América Latina. Además, durante más de treinta años ha laborado como conferencista en seminarios y congresos internacionales relacionados con la educación popular y la sistematización de experiencias. 
drive these political-pedagogical processes. From that political-pedagogical vision of a popular society project, we can talk about a popular education".

Keywords: Óscar Jara Holliday; Interview; Popular Education; Latin America; Social Studies; History.

\section{La educación popular}

Revista Perspectivas (RP): Don Óscar, ¿cuál es el principal objetivo de la educación popular?

Óscar Jara Holliday (OJH): Bueno, uno de los objetivos de la educación popular consiste en generar procesos de sensibilización acerca de problemáticas sociales, económicas, políticas o culturales determinadas.

RP: ¿En cuáles sectores de la sociedad debería ponerse en práctica esta perspectiva pedagógica?

OJH: Al respecto, hay que entender tres aspectos. Cuando hablamos de educación popular, deberíamos hablar de procesos de educación popular porque no existe una educación popular que sea igual en todo lado, sino que son procesos que van a depender mucho de diferentes contextos históricos, sociales, políticos, culturales, etc. Segundo, que esto viene de entender que los procesos de educación popular son un fenómeno sociocultural, principalmente latinoamericano, que se desarrolla desde hace muchísimos años y tiene antecedentes desde fines del siglo XIX, comienzos del siglo XX, cuando las organizaciones sociales -en este caso, principalmente, los sindicatos, el movimiento anarquista- fueron creando espacios de reflexión, espacios de formación vinculados a la dinámica de los movimientos. El movimiento sindical, incluso los movimientos políticos con el surgimiento de los partidos socialistas o comunistas en América Latina -en los años 15-20-30 del siglo pasado-, son movimientos que siempre iban incorporando un centro cultural, una biblioteca popular, cursos de formación, universidades populares, etc. Incluso hay un movimiento grande de universidades populares que se crean en la década de 1920, en varios países de América Latina -en Cuba, Perú, Argentina, Uruguay-, y estas universidades populares fueron las pioneras del proceso que luego se llamó extensión. Aunque, en realidad, la extensión fue promovida por la Reforma de Córdoba de 1918, de la cual ahora estamos conmemorando los primeros cien años, con la idea de que la universidad no debería ser un espacio cerrado y elitista, sino que debería estar vinculado con la dinámica de la sociedad. Bueno el de la extensión es un tema complejo, pero, en estos procesos, uno de los primeros procesos de extensión fueron las universidades populares, que primero eran espacios en que las universidades apoyaban a los movimientos, pero después fueron espacios creados por los propios movimientos, entonces eso ya existía desde antes. 
Hay antecedentes mayores que van hacia el surgimiento de las repúblicas en América Latina después de la independencia. Una aspiración general que hay en todos nuestros países es poder tener una educación pública -una instrucción pública- para toda la población. Puesto que, antes, quienes recibían la instrucción o la educación eran las clases nobles y la gente que venía de los colonos-colonizadores-conquistadores. Entonces, se abren las repúblicas y nace la idea, incluso Simón Bolívar y Simón Rodríguez -que era su principal mentor- empiezan a hablar de la necesidad de una instrucción pública y popular. Se empieza a utilizar el término de educación popular, pero dirigido a la instrucción pública generalizada, cosa que nosotros decimos ahora que eso es un valor republicano, un valor democrático que debemos defender; la educación pública, laica, gratuita e inclusiva.

Dichos antecedentes, luego del decenio de 1960, sufren una modificación en las dinámicas de los movimientos, producto principalmente de la influencia de la revolución cubana. La revolución cubana no es solamente algo que tiene un impacto para Cuba, sino que genera - a nivel de todo el continente- la apertura de posibilidades de que sí es posible tener una realidad distinta, "sí es posible... pues éramos países aristocráticos, controlados con una visión súper colonialista y nuestras propias repúblicas estaban muy limitadas y dependientes". Entonces, la revolución cubana abre la posibilidad, es una especie de ruptura epistemológico-política que dice, "bueno sí es posible que construyamos en América Latina otro tipo de realidades, otro tipo de sociedades". En este contexto empiezan a salir todos estos distintos movimientos; uno de ellos es el que Paulo Freire denomina educación liberadora.1 Paulo Freire va a criticar la idea de una educación domesticadora y en su texto principal Pedagogía del oprimido -que este año cumple cincuenta años su primera edición en 1968-, él precisamente aporta una visión que le da vuelta a la noción de la educación: en lugar de estar basada en la enseñanza, se va a referir a una educación basada en el aprendizaje, que en lugar de tener una relación autoritaria, hay que tener una relación democrática, dialógica entre educador-educando. Por lo tanto, los procesos de aprendizaje deben basarse en las realidades, que partan para conocer las realidades y en función de su transformación. Entonces ahí empiezan a aparecer procesos de educación liberadora. Liberadora en dos sentidos; por un lado, liberadora de los elementos que nos oprimen -que tenemos en realidades de opresión- y, por otro lado, también liberadora o libertadora digamos de nuestras potencialidades, de nuestras capacidades. Ese es como el doble sentido que va desarrollando el pensamiento de Freire, y a partir de ahí se empieza a generar todo un movimiento. Lo que pasa es que Paulo Freire es detenido en Brasil con el golpe militar de 1964; en ese momento, él había sido llamado para encargarse de un

1 Según Paulo Freire, esta educación tiene por ideal el desarrollo del pensamiento humano y la posibilidad de cuestionar la naturaleza y el entorno -el mundo según Freire- de su situación histórica y social. 
Plan Nacional de Alfabetización. Tenía una propuesta de alfabetización concientizadora, dialógica, crítica, que había puesto en práctica en el noreste de Brasil y se iba a hacer a nivel nacional, pero a los pocos meses que empezó esa propuesta viene el golpe y él se tiene que exiliar. Cuando él se va, hay un grupo de gente que queda trabajando el método de Paulo Freire de la educación liberadora y se vincula con el movimiento de educación popular y con la idea de que esta educación liberadora debe formar parte de las dinámicas de un movimiento popular latinoamericano. Por lo tanto, debían tener una orientación política y un sentido político. Entonces, finalizando la década de 1960, se crea el concepto de educación popular. No lo crea Paulo Freire -él siempre habla de educación liberadora-, pero ese mismo sentido es copiado y aparece ese término que empieza a divulgarse por toda América Latina.

A partir del decenio de 1970, en Chile se empieza con el gobierno de la Unidad Popular de Salvador Allende. Freire había ido antes con el gobierno de Frei a trabajar en programas de alfabetización, ya en el gobierno de Allende se empieza a pensar que podía haber una política pública -una reforma educativa- de carácter de educación popular. En Perú, hay un movimiento similar en 1968, hay un movimiento de militares progresistas que también plantean una reforma educativa vinculada con procesos de educación popular y, antes de ser reprimidos con las dictaduras impuestas en estos países -sobre todo, después del golpe de Estado en Chile en 1973-, empiezan a desarrollarse experiencias en Chile, en Argentina, en Uruguay de procesos de educación popular. La gente que se estaba dedicando a estas reformas pedagógicas se exilia, así como Freire fue exiliado de Brasil -y de ahí va para Bolivia, y de ahí va para Chile y después para Estados Unidos y Ginebra, Suiza-, muchos educadores y educadoras populares que estaban trabajando en teatro popular, en estos procesos de participación comunitaria, tienen que exiliarse. El exilio hace que los procesos de educación popular se expandan por toda América Latina, y el pensamiento digamos más estructurado de esto -que es el pensamiento de Paulo Freire- se difunde como la base de fundamentación de este proceso. De ahí sigue una dinámica larga durante las décadas de 1970 y 1980, cuando ocurre una expansión a nivel latinoamericano del enfoque de educación popular, sobretodo de movimientos de ONG que empiezan a crecer con apoyo de cooperación internacional -en este caso como nosotros aquí en ALFORJA-.2 Entonces sí se pudo empezar a impulsar proyectos de educación popular, ya no solo proyectos comunitarios, pequeños, sino proyectos incluso de alcance nacional. Cuando se da la Revolución Sandinista en 1979, se plantea que toda la educación en Nicaragua debería ser una educación popular, y entonces en ese momento ya se rompe la idea de que la educación popular era

2 Es la organización encargada de la educación popular y que trabaja de manera conjunta con la Red Alforja. Se le conoce como el Centro de Estudios y Publicaciones (CEP) Alforja. El CEP fue fundado en mayo de 1980 como el centro de educación popular en Costa Rica y como sede local en coordinación con la Red Alforja. 
una cosa y la educación formal era otra, sino que se podía hacer una educación popular desde la educación pública.

Ahora bien, ¿qué entendemos por educación popular?, ¿por qué hablamos de lo popular? Considero que utilizamos tres sentidos de lo popular. Hay un primer sentido de lo popular referido a pueblo, referido a toda la gente. La educación popular debería ser una educación que llegue a todas las personas, en ese sentido, una educación pública, gratuita, laica, inclusiva y de calidad, que es un poco la pelea que estamos teniendo para defender esa educación pública en todos los niveles, desde preescolar hasta todos los niveles, que es lo que se conoce como una educación para toda la vida - de la universidad incluso. Es un derecho democrático y por lo tanto debería haber una educación popular en ese sentido.

Hay una segunda noción de lo popular que son los sectores populares, que es lo que Helio Gallardos llama "el pueblo social", que son -según dice Helio Gallardo-: todos aquellos sectores que sufren algún nivel de asimetría son pueblo, en el sentido de sector popular. Asimetría por razones económicas, o sea explotados económicamente, porque tienen un tipo de opresión política, por algún tipo de discriminación, de marginación, todos esos conformarían los sectores populares. Entonces, una educación popular -en ese segundo sentidodebería ser una educación que llega, principalmente, que tiene como prioridad, como principales sujetos de su participación, a los sectores populares. La educación popular no solamente es universal, sino que es una educación para esos sectores.

Una tercera noción de lo popular es que esta educación debería tener una noción política transformadora, es decir, una educación que debería permitir que la sociedad pudiera tener una estructura social, democrática, justa, equitativa y que, por lo tanto, los sujetos protagonistas de los procesos educativos tienen que ser quienes impulsen esos procesos político-pedagógicos. De esa visión político-pedagógica de un proyecto popular de sociedad, podemos hablar de una educación popular. Si tomamos en cuenta esto, podemos decir que toda educación debería ser popular en alguno de estos sentidos, y ojalá combinados entre los tres: una educación pública, gratuita, de calidad, para todo el mundo, que tenga como prioridad los sectores populares y que tenga como orientación política la transformación en función de un modelo utópico de justicia, de sociedad justa y de equidad, con participación, con respeto a la diversidad, etc. Entonces, es un modelo de sociedad.

Esto quiere decir que se puede hacer con grupos pequeños de personas, o se puede hacer a nivel de una política nacional que se puede trabajar con todas las temáticas posibles. Podemos hacer educación popular en ciencias, en derecho, en cibernética, informática y no solamente en las tradicionales

3 Filósofo y escritor chileno con amplios trabajos en política popular latinoamericana y realidad social. Reside en Costa Rica desde 1973 y ha sido profesor de la Universidad de Costa Rica, la Universidad Nacional de Costa Rica y la Universidad Estatal a Distancia de Costa Rica. 
ciencias sociales. Podemos hacer educación popular vinculándonos con los saberes indígenas, con los saberes campesinos, o saberes populares que la gente tiene en las comunidades urbanas. Podemos hacer educación popular en colegios, en universidades, en escuelas, en preescolares, con población de la tercera edad... O sea, esta noción que tenemos nosotros ahora de educación popular implica que es otra concepción de educación. No solamente un fenómeno sociocultural que tiene una historia, sino que además es una concepción de educación que tiene una propuesta ética, una propuesta política de un sentido por el cual se orienta y una propuesta pedagógica para ser coherente con ese proceso. Por esta razón, una educación popular no podría ser unilateral, autoritaria, dogmática, memorística. Una educación popular debe ser pedagógicamente activa, tiene que ser dinámica, tiene que ser dialógica, deconstructiva, tiene que ser un proceso en el cual todas las personas son sujetos protagonistas de aprendizaje, vinculadas a las problemáticas que debemos enfrentar.

RP: ¿Para trabajar en un proceso de educación popular se tiene que ser necesariamente docente profesional?

OJH: Cualquier persona que tiene un conocimiento, o una responsabilidad con un grupo, puede impulsar procesos de educación popular. Ahora bien, un docente, una docente, con mayor razón que su función principal es realizar procesos pedagógicos, pero tienen que ser procesos político-pedagógicos. Pero, por ejemplo, un presidente de la República, un dirigente sindical o una dirigente sindical, un ministro o una ministra, deberían pensar procesos de educación popular, que su orientación, que su visión de país o de procesos en los cuales están insertados, sean elementos formativos que nos desarrollen como ciudadanos críticos, responsables y participativos. Por eso, los procesos de cualquier nivel de educación popular tienen que ser procesos de participación. Pero si yo participo intensamente en un proceso, yo voy a necesitar y voy a exigir participar en todos los procesos de mi vida social. La labor de un diputado, una diputada, debería ser sentir que tiene una tarea de educación popular. No necesariamente que sea definido como un educador popular, pero tiene una dimensión en su trabajo. Es decir, que lo que yo hago en mi curul es algo que tiene que ver con procesos de formación que vinculo con procesos de sociedad, con proyectos que se discuten y que deben tener la participación de la gente para poder orientarse en ese sentido.

Hay tareas específicas de educación popular, y hay una dimensión general de procesos de educación popular que deberían marcar el rumbo de una sociedad democrática, porque una educación popular es necesariamente democrática, y una educación popular es necesariamente democratizadora y dinamiza nuestras capacidades críticas de la democracia. Por consiguiente, no puede haber nada más antipopular que una educación autoritaria, memorística, o una sociedad que te impida desarrollar un pensamiento crítico. 
Las universidades, los centros de investigación y las revistas son instrumentos para procesos de educación popular, en alguno de los sentidos que estamos hablando. 